\title{
Street on evolution and the normativity of epistemic reasons
}

\author{
Daan Evers ${ }^{1}$
}

Received: 28 August 2014 / Accepted: 5 March 2015 / Published online: 24 March 2015

(C) The Author(s) 2015. This article is published with open access at Springerlink.com

\begin{abstract}
Sharon Street (Can J Philos Suppl Vol 35: 213-248, 2009) argues that realism about epistemic normativity is false. Realists believe there are truths about epistemic reasons that hold independently of the agent's (or anyone else's) attitudes. Street argues by dilemma. Either the realist accepts a certain account of the nature of belief, or she does not. If she does, then she cannot consistently accept realism. If she does not, then she has no scientifically credible explanation of the fact that our epistemic behaviours or beliefs about epistemic reasons align with independent normative truths. I argue that neither horn is very sharp for realists about epistemic normativity.
\end{abstract}

Keywords Sharon street · Epistemic normativity · Epistemic reasons ·

Evolution · Moral realism and antirealism

Some powerful recent defences of moral realism appeal to the similarities between moral and epistemic normative discourse (e.g. Shafer-Landau 2006; Cuneo 2007). For example, Terence Cuneo (2007) thinks the categorical nature of epistemic reasons undermines Mackie's (1978) argument from queerness against moral reasons. The idea is roughly that neither moral nor epistemic reasons can be reduced to naturalistic relations, and that both are, as a matter of conceptual fact, categorical (binding irrespective of the desires, policies or beliefs of agents). Whereas it might seem plausible to deny the existence of moral reasons, it would not be plausible to deny the existence of epistemic reasons. One reason for this is that if there were no epistemic reasons,

Daan Evers

h.w.a.evers@rug.nl

1 Faculty of Philosophy, University of Groningen, Oude Boteringestraat 52, 9712 GL Groningen, The Netherlands 
then no view whatsoever would be justified (including Mackie's error theory). However, once one allows that there are some categorical reasons, the force of appeals to categoricity as an objectionably queer property is diminished in the case of morals.

So it matters to debates about moral realism that realism about epistemic reasons is both possible and plausible. Street (2009) argues that this is not the case. She distinguishes two kinds of realism. The realist about Cliffordian normativity believes that facts bearing on the truth of a proposition $\mathrm{P}$ have the status of being epistemic reasons for or against believing $\mathrm{P}$, and that this is so independently of an agent's evaluative attitudes. The normative realist about likelihood thinks that claims about probability are normative claims, and that they are true independently of an agent's evaluative attitudes. Street raises a dilemma for both views: either the realist accepts the "constitutivetakings account" of the nature of belief, or she does not. If she does, then she cannot consistently accept realism. If the realist rejects the constitutive-takings account, then she would lack a credible explanation of the fact that our epistemic behaviours and beliefs about epistemic reasons correspond to mind-independent normative truths. I argue that neither horn is very damaging for realists about epistemic normativity.

\section{Two kinds of realism about epistemic normativity}

Street notes that the claim fact $F$ is a reason to believe $P$, 'conceals' two importantly distinct claims (p. 219):

Claim 1: Fact F makes it more likely that $\mathrm{P}$

and

Claim 2: In virtue of F's making it more likely that P, F is a reason to believe that $\mathrm{P}$.

Street thinks there are two kinds of realism corresponding to these claims: "the realist may view either Claim 1 or Claim 2 (or both [...]) as an independently true substantive normative claim' (p. 220). By an 'independent' claim, Street means that the claim is true irrespective of an agent's (presumably any agent's) actual or hypothetical evaluative attitudes.

Realists who take Claim 2 to state an independent normative truth believe that:

on the assumption that $\mathrm{F}$ makes it more likely that $\mathrm{P}, \mathrm{F}$ is, in virtue of that, a normative reason to believe that $\mathrm{P}$, and that this is so no matter what an agent's evaluative attitudes are or what follows from within the standpoint constituted by them. (2009, p. 221)

Street calls this realism about Cliffordian normativity (since William Clifford thought we had a moral obligation to form beliefs only on the basis of considerations bearing on their truth). ${ }^{1}$ Cliffordian realists, then, think it is an attitude-independent truth that considerations bearing on the likelihood of $\mathrm{P}$ are epistemic reasons with respect to $\mathrm{P}$.

\footnotetext{
1 Strictly speaking, realism about epistemic reasons need not involve any substantive beliefs about which considerations count as epistemic reasons for or against a belief. (Thanks to Folke Tersman for this point.) However, the substantive commitments identified in the quotation play a role in Street's dilemmas.
} 
Street also attacks a certain realist view with respect to claims like 1. According to this view, claims about likelihoods are normative claims. So, for example, 'F makes it more likely that P' might mean that one ought to raise one's degree of belief in $\mathrm{P}$ in the light of F. Or the realist might say that statements about what is more likely are statements about what there is more reason to believe. Street calls this Normative Realism about Likelihood:

Truths concerning "what makes what more likely" are normative truths concerning what there is most normative reason to believe, and these truths hold no matter what an agent's evaluative attitudes are or what follows from within the standpoint constituted by them. (2009, p. 237)

Street argues that both realism about Cliffordian normativity and normative realism about likelihood are false. Her arguments against both forms of realism are very similar and take the form of a dilemma. I will start with her dilemma for realists about Cliffordian normativity. Once I've discussed this dilemma, it won't take long to explain my reservations about her objections to normative realism about likelihood (Sect. 3).

\section{Street's dilemma for realism about Cliffordian normativity}

\subsection{First horn: the constitutive-takings account of belief}

Streets notes that if someone professed to believe that $\mathrm{P}$ but did not take considerations bearing on P's likelihood to be reasons for or against believing P, this would give us reason to doubt that she really believed P. So it seems constitutive of believing $\mathrm{P}$ that facts bearing on the likelihood of $\mathrm{P}$ are treated as reasons for or against belief in $\mathrm{P}$. This makes it plausible that ascribing a belief that $\mathrm{P}$ to $\mathrm{S}$ involves the claim that $\mathrm{S}$ takes considerations bearing on P's truth to be reasons for or against believing P (note that judging that someone takes certain facts to be reasons is not itself a normative claim).

The claim that it is constitutive of believing $\mathrm{P}$ that one takes considerations bearing on P's truth to be epistemic reasons with respect to $\mathrm{P}$ is what Street calls the constitutivetakings account of belief. According to her, realism about Cliffordian normativity is incompatible with this account. The Cliffordian realist believes it is an objective (attitude-independent) normative fact that considerations bearing on the truth of $\mathrm{P}$ are epistemic reasons with respect to P. To show why this is incompatible with the constitutive-takings account, Street asks us to imagine agents who deny that facts bearing on the likelihood of $\mathrm{P}$ are epistemic reasons with respect to $\mathrm{P}$. One agent she introduces is Ben, who claims to believe that there is intelligent life on the moon:

let's imagine that Ben-both as a fairly routine, unconscious matter, and when he thinks about the question in full consciousness-regards considerations bearing on the truth of $\mathrm{P}$ as having no normative relevance to the question whether to believe that $\mathrm{P}$, and instead regards all and only considerations about what's amusing to be reasons for and against belief that P. (It's on this basis that he believes that there is intelligent life on the moon: he finds the idea amusing.) (2009, p. 227) 
According to Street, the constitutive-takings account 'doesn't accuse [Ben and others like him] of making a substantive normative mistake about what reasons there are for their genuine belief that $\mathrm{P}$, but rather merely asserts the conceptual claim that such people don't count as genuinely believing that $\mathrm{P}$ at all [...]' (2009, p. 228). Street concludes that ' $[\mathrm{t}]$ his is not a realist view about Cliffordian normativity':

One way of putting the point is to say that if the constitutive-takings account is right, then it is conceptually impossible to go badly wrong with respect to the alleged independent normative truth in question, according to which considerations bearing on the truth of $\mathrm{P}$ are reasons for and against belief that P. (p. 229)

Street argues that if you accept the constitutive-takings account and Ben professes to believe that there is intelligent life on the moon, then he is wrong only in the sense that he misapplies the concept of belief (he does not really believe that there is intelligent life on the moon). ${ }^{2}$ But he would not make a mistaken normative judgement about what counts as reasons for his belief.

\subsection{Assessment of horn 1}

I think Street's argument here is less than transparent. Why should it matter to the attitude-independence of the Cliffordian claim whether people like Ben can contradict it? There seem to be at least four different arguments that Street may have had in mind.

Argument 1 Given the constitutive-takings account, Claim 2 is not a normative claim. It is merely a claim about how people with beliefs with respect to $\mathrm{P}$ treat considerations that bear on P's truth. If so, then there is no normative truth one can be a realist about in the first place.

It seems to me that even if there is a reading of Claim 2 on which it is not normative, there is also a reading on which it $i s$. We can understand it as the claim that facts that raise the likelihood of $\mathrm{P}$ favour belief in $\mathrm{P}$. So long as the notion of favouring has a normative use in some contexts where we talk about reasons, it should be applicable in the context of reasons for belief as well (it seems ad hoc to suppose otherwise). The realist about Cliffordian normativity could say that this normative claim about favouring is true independently of anyone's attitudes.

Argument 2 The realist believes that Claim 2 is a normative truth that holds independently of the agent's evaluative attitudes. This entails that if the agent did not take the fact that $\mathrm{F}$ raises the likelihood of $\mathrm{P}$ as a reason to believe $\mathrm{P}$, it would nonetheless be a reason for her to believe P. However, if the constitutive-takings account of belief is true, then this claim is false. If you do not (more or less systematically) take facts that raise the likelihood of $\mathrm{P}$ as reasons to believe that $\mathrm{P}$, then you don't count as someone with beliefs at all. But then you don't have any reasons to believe P.

\footnotetext{
2 If the constitutive-takings account is true, then Ben does not have any beliefs at all. The reason is that Ben systematically treats only considerations bearing on whether it is amusing to believe something as reasons for belief. Having no beliefs at all may entail that he also lacks the concept of belief, but it certainly implies that he does not apply it to himself (at least not insofar as "applying a concept" entails having a belief).
} 
It seems to me that the realist could respond as follows: what matters with respect to independence is that the favouring-relation holds for someone capable of belief not in virtue of the fact that the agent has certain attitudes (although it is also true that if she did not have these attitudes, then she would not have any epistemic reasons). That there is some condition under which a reason applies to someone does not always throw doubt onto the objective nature of the favouring-relation: moral reasons to $\mathrm{X}$ do not apply to someone incapable of X-ing (in the circumstances) in the sense that that person is not doing anything wrong by not X-ing. But that the relevant facts favour $\mathrm{X}$-ing (for people capable of X-ing) need not hold in virtue of the evaluative attitudes of the agent. Similarly, although someone incapable of belief does not do anything wrong by failing to conform or adjust beliefs to facts about likelihoods, nevertheless that such facts count in favour of or against belief for someone capable of belief need not depend on the agent's (or anyone else's) evaluative attitudes.

Argument 3 Cliffordian realism about epistemic reasons requires that it is a mindindependent fact that considerations bearing on the likelihood of $\mathrm{P}$ are epistemic reasons with respect to $\mathrm{P}$. In order for something to be a mind-independent fact it must be conceptually possible that it obtains and for someone to believe that it does not. But if the constitutive-takings account is true, then it is not conceptually possible for anyone to believe that it is not the case that considerations bearing on the likelihood of $\mathrm{P}$ are epistemic reasons with respect to $\mathrm{P}$. After all, someone who does not treat such considerations as epistemic reasons would not have any beliefs at all. ${ }^{3}$

Even if we accept the definition of mind-independence employed here, the reasoning is questionable. There seems to be a difference between treating considerations bearing on the likelihood of a proposition as epistemic reasons and having the belief that such considerations are epistemic reasons. The former seems a matter of policy that even children and animals can implement, while the latter requires complex conceptual resources (such as the concept of belief, likelihood and epistemic reason). If treating considerations as epistemic reasons is indeed a matter of policy rather than beliefs, then it is unclear why one could not be disposed to implement this policy while also believing that it is not the case that considerations bearing on the likelihood of $\mathrm{P}$ are epistemic reasons with respect to $\mathrm{P}^{4}$ Of course, the constitutive-takings account suggests that one cannot have this latter belief unless one treats considerations bearing on its likelihood as epistemic reasons. But why should the account rule out this possibility?

A plausible version of the constitutive-takings account should allow that people sometimes form and adjust beliefs on the basis of non-epistemic considerations. What is required to count as believing $\mathrm{P}$ is that one has a (strong) disposition to treat considerations bearing on the likelihood of $\mathrm{P}$ as epistemic reasons with respect to it. This is consistent with forming the belief on the basis of non-truth-relevant considerations, while having a disposition to adjust it on the basis of truth-relevant considerations.

\footnotetext{
3 I owe this interpretation of Street's argument to Krister Bykvist.

4 This belief may be hard to act on, somewhat in the way in which an error theorist might be irresistably drawn to moralizing while believing that all interesting moral claims are false.
} 
And so the constitutive-takings account does not rule out that someone can believe that it is not the case that facts bearing on the likelihood of $\mathrm{P}$ are epistemic reasons with respect to $P$.

Furthermore, the notion of mind-independence used in Argument 3 is dubious. It says that a fact is mind-independent if and only if it is conceptually possible that the fact obtains and someone believes that it does not. But suppose there were no sentient beings. It is not conceptually possible that this fact obtains while someone believes that it does not. This hardly shows that the non-existence of sentient beings would depend on anyone's beliefs or evaluative attitudes. So Cliffordian realists should not be concerned about this notion of mind-independence.

Realists about normative facts (at least realists of the kind Street is interested in) tend to embrace notions of mind-independence along the following lines: a normative property or relation is mind-independent iff its essence does not involve (relations to) human attitudes (Wedgwood 2007). Similarly, one might say that a normative property is mind-independent iff its being exemplified by a thing or situation (which might itself involve subjective mental states) is not dependent on anyone's actual or hypothetical attitudes (Shafer-Landau 2003, p. 15, Kirchin 2012, p. 22). Nothing in Street's arguments rules out that it is a mind-independent fact in these senses that facts that raise the likelihood of $\mathrm{P}$ are epistemic reasons to believe $\mathrm{P}$.

Let me briefly discuss one more argument for the incompatibility between the constitutive-takings account of belief and realism about Claim 2:

Argument 4 The normative reading of Claim 2 is itself true in virtue of the nature of belief. If so, there is no theoretical need to ground it in something else as well (such as non-natural facts about reasons).

It seems doubtful that Street could have intended this argument, since she does not explain how the constitutive-takings account entails that facts that raise the likelihood of propositions are epistemic reasons (nor is it clear how this further conclusion could be derived.) All she has shown is that if the constitutive-takings account is true, then you cannot count as a believer unless you treat facts that bear on the likelihood of propositions as reasons for or against believing them.

Perhaps Street would say that the constitutive-takings account suggests that a claim like:

If $\mathrm{F}$ makes it more likely that $\mathrm{P}$, then $\mathrm{F}$ is an epistemic reason to believe $\mathrm{P}$ expresses a hypothetical imperative, such as this:

If you are interested in having beliefs with respect to $\mathrm{P}$, then if $\mathrm{F}$ makes it more likely that $\mathrm{P}$, you ought to treat $\mathrm{F}$ as relevant to belief in $\mathrm{P}$.

However, even if one could ground this hypothetical imperative in the nature of belief, it is unclear why the constitutive-takings account rules out a non-hypothetical reading of the conditional. Furthermore, it is not as if realism about epistemic normativity cannot be formulated in different ways than by means of Claim 2. For example, the realist could say that certain facts favour the formation of beliefs irrespective of the attitudes of agents. 
So it seems that none of the four arguments discussed above clearly undermines realism about Cliffordian normativity. ${ }^{5}$ If so, then the first horn of Street's dilemma is not very sharp. I think the same goes for the second horn.

\subsection{Second horn: evolution}

On the second horn of Street's dilemma, the realist assumes that the constitutivetakings account of belief is incorrect. This means that it is conceptually possible for someone systematically to treat considerations bearing on the truth of $\mathrm{P}$ as irrelevant to the question whether to believe $\mathrm{P}$, and yet she may still believe that P. A realist about Cliffordian normativity will say that this person would be wrong in basing her beliefs on other considerations, but such a person is not impossible. If so, then

the following becomes a legitimate scientific question: How, as a matter of causal explanation, did it come to be the case that we so regularly take considerations having to do with truth and falsity - rather than some other, very different sort of consideration - to count in favour of the attitude of belief? As a conceptual matter, we're now assuming, it's possible that we could have done otherwise: we can imagine an individual, or indeed the whole human population, systematically taking considerations other than ones having to do with truth and falsity as normative reasons for belief. So we are now entitled to ask why, simply as a causal matter, we didn't end up like this. (2009, p. 232)

Street thinks the realist about Cliffordian normativity has no scientifically acceptable answer to this question.

One option for the realist would be to say that it is simply a coincidence that the considerations we evolved to treat as relevant are actually objectively relevant. But this would be improbable, given the range of things that are conceptually possible: we might have based our beliefs on what is amusing, exciting, soothing, silly, etc. Given this range, it would be incredible to suggest that the forces at work in evolution would have aligned our actual epistemic behaviours with the independent normative truth merely by chance.

Street thinks the realist will have to provide a tracking explanation, according to which it is beneficial to track the objective normative truth (Claim 2). The idea is that creatures that do so are more likely to survive and procreate than creature that do not. This may initially seem plausible, as creatures that base their beliefs on information relevant to their truth are more likely to represent their environment accurately, which will increase their chances of survival and procreation.

However, Street thinks the tracking explanation is clearly inferior to the adaptivelink account which does not appeal to an independent normative truth about epistemic

\footnotetext{
5 Another possible argument (though probably not Street's) is this: if the constitutive-takings account of belief is true, then people who fail to treat considerations bearing on the truth of $\mathrm{P}$ as relevant to belief in $\mathrm{P}$ do not really make a normative mistake. But it only makes sense to speak of a norm if it can be broken. So: Claim 2 cannot express a norm. This argument is not very good. The norm according to which facts that raise the likelihood of $\mathrm{P}$ favour belief in $\mathrm{P}$ can be broken even if it only applies to creatures capable of beliefs. After all, these creatures may on occasion fail to form beliefs on the basis of facts about likelihoods, even they are disposed to form beliefs on the basis of such facts.
} 
reasons at all. According to this account, creatures that formed beliefs on the basis of information relevant to their truth were more likely to have true beliefs and thus more likely to survive and reproduce. This by itself explains why we ended up taking considerations bearing on the truth of propositions as reasons for or against belief in those propositions. No need to appeal to independent normative truths at all.

Street thinks the adaptive-link account defeats the tracking account as a scientific explanation of why we ended up taking truth-relevant considerations as reasons for or against belief. The former would be clearer, more parsimonious, and have greater explanatory power.

\subsection{Assessment of horn 2}

Need the realist say that the fact that we take truth-relevant considerations to be reasons for belief is explained by the fact that we have evolved to track an independent normative truth? This suggests that we treat truth-relevant considerations in the way we do only because we (evolved to) have access to an independent truth about them. I don't think the realist has to say this. The realist can accept Street's parsimonious explanation of our beliefs about what counts as epistemic reasons, and also hold that there are independent normative truths about such reasons (of course the realist does need some reason to postulate such truths in the first place). The reason why the realist can accept Street's parimonious explanation of our beliefs about epistemic reasons is that given that Claim 2 is independently true, and creatures that form beliefs on the basis of truth-relevant considerations are more likely to survive and reproduce, it is no wonder that what we evolved to treat as epistemic reasons coincides with the independent normative truth. This is so even if it is false that we came to be the way we are because tracking the independent normative truth was itself selected for.

The foregoing is right if we assume that the independent normative truth has the content of Claim 2. A different question is how we know that the independent normative truth has this content. Street may want to say that our intuitions with respect to this truth are unreliable ${ }^{6}$ given that natural selection does not favour access to independent normative truths per se (as she argues with respect to moral truths in 2006).

However, this skeptical argument is not clearly successful. Even if the realist rejects the constitutive-takings account of belief, she can still place restrictions on what can count as a reason for belief. The restrictions will not in that case be grounded in facts about the nature of belief, but the realist can give different grounds. For example, it is plausibly a conceptual truth that epistemic reasons are considerations bearing on the likelihood of a proposition. The latter view will almost certainly be taken by Cuneo and Shafer-Landau, as they defend this kind of idea even with respect to certain moral truths which are much more controversial (the idea that there is a much larger number

\footnotetext{
6 Or at least that we have no reason to think our intuitions are reliable. This is distinct from claiming that evolution gives us reason to think our intuitions are unreliable (thanks to Folke Tersman for this point). Of course, a simple argument would get us from the fact that evolution gives us no reason to think our intuitions are reliable to the conclusion that they are unreliable. This argument presupposes that there is a vast number of conceptually possible truths about epistemic reasons. I dispute this premise in the main text.
} 
of moral conceptual truths than is often assumed was prefigured in Shafer-Landau 2012, and worked out in greater detail in Cuneo and Shafer-Landau 2014).

An interesting question is how the idea that Claim 2 is conceptually true relates to the idea that it is mind-independently true. We can gather how Cuneo and Shafer-Landau would answer this question from the following passage:

[According to the traditional Fregean view of concepts,] concepts are not mental or linguistic entities. They are not ideas in the head, sentences in the brain, or anything of that sort. Rather, they are abstract, sharable, mind-independent ways of thinking about objects and their properties. As such, they are very much objective, "out there" sorts of things, extra-mental items whose existence does not depend on our employing them in thought or language. (2014)

Cuneo and Shafer-Landau appeal to a very general view of concepts in order to motivate what they call non-naturalism about morals. Since they believe conceptual truths are grounded in the essences of concepts and concepts are themselves mind-independent entities, moral conceptual truths are also mind-independent. The same would hold for epistemic conceptual truths: they too can be grounded in the essences of concepts, and since concepts are plausibly mind-independent, so are these truths.

So the idea that Claim 2 is a conceptual truth is compatible with the idea that it is a mind-independent truth as well. And there are other ways for the realist to place restrictions on what could count as an epistemic reason without appeal to the constitutive-takings account of belief. For example, if it is not implausible that considerations bearing on likelihood are epistemic reasons as a matter of conceptual fact, it is not implausible either that such truths hold in virtue of the essence of the property of being an epistemic reason. This would also help to motivate the view that Claim 2 is not a conceptual truth, but synthetic a priori. Whatever faculty allows us to have synthetic a priori knowledge may itself be related to our general capacity for forming views about the world, the reliability of which is beneficial from an evolutionary standpoint (Shafer-Landau 2012, p. 30). If so, then our judgements about epistemic reasons inherit their reliability from the reliability of our general faculties of reasoning.

So the skeptical worry that if there are mind-independent truths about epistemic reasons, then we would not be in a position to know them is not clearly successful. But this was probably not Street's concern to begin with. Her concern was the realist's explanation of our beliefs about epistemic reasons: if it is a mind-independent truth that facts that raise the likelihood of $\mathrm{P}$ are epistemic reasons for belief in $\mathrm{P}$, how did we end up treating such facts as epistemic reasons? The realist would lack a credible scientific explanation. I have argued that the realist can appeal to the same explanation as Street does, so that Street is not in a better position with respect to this question. So it seems that realism about Cliffordian normativity can survive Street's dilemma.

\section{Street's dilemma for normative realism about likelihood}

Normative realists about likelihood interpret claims about likelihood as normative claims. For example, normative realists might say that 
(1) The fact that $n / m$ of the observed Xs have been Y makes it more likely that $n / m$ of the unobserved Xs are $\mathrm{Y}$

really means:

(1*) The fact that $\mathrm{n} / \mathrm{m}$ of the observed Xs have been $\mathrm{Y}$ is a reason to believe that $\mathrm{n} / \mathrm{m}$ of the unobserved Xs are Y.

Normative realists about $(1 *)$ would say that the relevant fact is such a reason no matter what follows from the agent's evaluative attitudes or the perspective constituted by them. Street does not object to normative interpretations of claims about likelihood per se, but she does object to realism about such interpretations. Her argument is very similar to her dilemma for realists about Cliffordian normativity, although she does not explicitly discuss the first horn of the dilemma in the context of normative realism. I take it, however, that this horn would go something like this:

Suppose the normative realist about likelihood accepts the constitutive-takings account of belief. In that case, one cannot go very far wrong with respect to judgements about what constitutes a reason for belief while still counting as someone who has beliefs (about the relevant subject matter) at all. For example, someone who treated the fact that $\mathrm{n} / \mathrm{m}$ of the observed Xs have been Ys as a reason to believe that $\mathrm{n} / \mathrm{m}$ of the unobserved Xs are not-Y would not make a mistaken normative judgement how certain facts bear on beliefs about the nature of Xs, but would not have any beliefs about Xs at all.

As before, it is not clear how this argument bears on the question whether normative truths about reasons are independent of evaluative attitudes. For example, it does not seem plausible that if the constitutive-takings account is true, then $(1 *)$ could not express a normative truth at all, but only a descriptive truth about how people with beliefs treat facts about the proportion of observed Xs (this would be the analogue of Argument 1 in Sect. 2.2).

The analogue of Argument 2 would be this: the normative realist about likelihood claims that $\left(1^{*}\right)$ is an independent normative truth. This entails that even if $\mathrm{S}$ did not (more or less systematically) take the fact that $\mathrm{n} / \mathrm{m}$ of the observed Xs have been $\mathrm{Y}$ as a reason to believe that $\mathrm{n} / \mathrm{m}$ of the unobserved Xs are $\mathrm{Y}$, it would still be such a reason for S. But this is false. After all, if $\mathrm{S}$ did not take the fact that $\mathrm{n} / \mathrm{m}$ of the observed Xs have been $\mathrm{Y}$ as a reason to believe that $\mathrm{n} / \mathrm{m}$ of the unobserved $\mathrm{Xs}$ are $\mathrm{Y}, \mathrm{S}$ would not be capable of beliefs at all and thus not have any epistemic reasons.

As before, the realist could respond as follows: that there is some condition under which a reason applies to someone does not always throw into doubt the objective nature of the favouring-relation: moral reasons to $\mathrm{X}$ do not apply to someone incapable of $\mathrm{X}$-ing in the sense that that person is not doing anything wrong by not X-ing. But that the relevant facts favour $\mathrm{X}$-ing for people capable of $\mathrm{X}$-ing need not hold in virtue of the evaluative attitudes of the agent. The same is true for facts about the number of observed Xs that were Y. They favour beliefs concerning the number of unobserved $\mathrm{Xs}$, but not because someone capable of beliefs treats them in this way.

Next, Street might have meant that if the constitutive-takings account is true, then normative facts about likelihood cannot be mind-independent in the sense that is conceptually possible that they obtain and for someone to believe that they do not (Argument 3). However, I have already argued that this notion of mind-independence 
is unattractive and that a plausible version of the constitutive-takings account will allow that it is conceptually possible for someone to believe the negation of statements like $\left(1^{*}\right)$.

Finally, the analogue of Argument 4 would be to say that it follows from the constitutive-takings account of belief that $\left(1^{*}\right)$ is itself true in virtue of the nature of belief. But, again, Street does not explain why that follows from the account, and it is not obvious how the derivation would go. So it seems that Street's first horn of the dilemma for normative realists about likelihood is not persuasive for the same reasons as the first horn of her dilemma for realists about Cliffordian normativity. I think the same goes for the second horn.

The second horn would proceed on the assumption that the constitutive-takings account of belief is false. This means it is conceptually possible for there to be people capable of beliefs who treat the fact that $\mathrm{n} / \mathrm{m}$ of the observed Xs have been $\mathrm{Y}$ as something other than a reason to believe that $\mathrm{n} / \mathrm{m}$ of the unobserved Xs are Y. For example, they may treat it as a reason to believe that $1-n / m$ of the unobserved Xs are Y. As a matter of fact, though, people tend not to do this. So the question arises what explains why our epistemic behaviours are the way they are, and why we believe that certain facts are epistemic reasons. Street thinks the realist has to say that it was somehow beneficial to track independent normative truths. But there seems to be a more parsimonious explanation: people who do not take the fact that $\mathrm{n} / \mathrm{m}$ of the observed Xs were $\mathrm{Y}$ as a reason to believe that $\mathrm{n} / \mathrm{m}$ of the unobserved Xs are $\mathrm{Y}$ tend to do worse in the struggle for survival. For example, if you do not take the fact that all tigers in the past have been dangerous as a reason to think other tigers are too, then you are less likely to avoid tigers, which in turn might have detrimental effects on your health and ability to procreate.

This argument is unpersuasive for the same reason as Street's second horn for the realist about Cliffordian normativity. The realist need not say that tracking the independent normative truth about reasons is itself beneficial from an evolutionary standpoint. But given that the independent truth has the content that $\mathrm{n} / \mathrm{m}$ of the observed $\mathrm{Xs}$ have been Ys is a reason to believe that $\mathrm{n} / \mathrm{m}$ of the unobserved Xs are $\mathrm{Y}$, it is not hard to explain why this tends to be what people believe as well: people who did not believe it were selected against (and mutatis mutandis for other claims about epistemic reasons).

Again, a different question is how we know that the independent normative truth has this content in the first place. Since evolutionary pressures favour only useful beliefs, why should our beliefs about epistemic reasons correspond to independent normative truths?

As before, the normative realist about likelihood may place restrictions on the way in which facts bear on belief. These restrictions will not derive from the fact that it is constitutive of belief that one treats these facts in precisely this way. But they may derive from other things. For example, if it is a conceptual truth that facts that raise the likelihood of $\mathrm{P}$ are reasons to believe $\mathrm{P}$ (as seems plausible), and if the fact that $\mathrm{n} / \mathrm{m}$ of the observed Xs have been Ys makes it more likely that $\mathrm{n} / \mathrm{m}$ of the unobserved Xs are $\mathrm{Y}$, then we are able to know that it is an epistemic reason to believe the latter through our knowledge of conceptual truths and likelihoods. And there are other options: the realist may be able to place restrictions on what can count as epistemic reasons 
through the correctness conditions of belief. If a belief is correct only if it is true and certain facts (e.g. facts about the observed Xs) relate in truth-relevant ways to other facts (e.g. facts about the unobserved Xs), we may be able to know that such facts are epistemic reasons through our knowledge of the correctness conditions of belief. Finally, the realist could speculate that we have access to independent normative truths through rational faculties that were themselves selected for. Beliefs about epistemic reasons might be synthetic a priori, and thus possible through whatever faculty makes this kind of judgement possible. Such a faculty may itself be related to our general capacity for forming views about the world, the reliability of which is beneficial from an evolutionary point of view. If so, then our judgements about how facts about the observed bear on beliefs about the unobserved may inherit their reliability from the reliability of our general faculties of reasoning.

\section{Parsimony}

I have argued that Street's dilemma is not very sharp for realists about epistemic normativity. However, Street may still be in a better position with respect to one issue: ontological parsimony. Whereas realists postulate mind-independent normative truths about epistemic reasons, Street does without them. ${ }^{7}$ So long as we lack a good reason to postulate such entities, we should prefer a theory along antirealist lines. I think this is correct: the realist does need a reason to postulate mind-independent normative truths. However, Street's dilemma by itself does not address the possibilities. One such possibility is the following: we have reason to accept mind-independent normative truths about epistemic reasons because some of them are conceptual truths, and concepts are mind-independent. This suggestion would at least move the debate between realists and antirealists about moral and epistemic normative truths to a general metaphysical debate about the existence of concepts and abstract entities.

Other reasons are also in the offing: Cuneo (2007) has offered many reasons why the best analysis of moral and epistemic language involves categoricity. If so, we face the question whether all moral and epistemic claims are false. Moorean arguments (discussed in Olson 2014, Chap. 7) could be brought against this. A Moorean argument is very simple:

(1) It is a fact that torturing babies for fun is wrong.

(2) So, there is at least one moral fact.

The idea behind this sort of argument is that it is not clearly more plausible that there are no moral facts than that torturing babies for fun is wrong. Since-if arguments along the lines of Cuneo (2007) are successful - the truth of (1) requires the existence of mindindependent normative facts, we have reason to accept at least one mind-independent normative fact. A similar argument could be used to establish the existence of mindindependent epistemic facts. The assumption is, again, that there are powerful reasons

\footnotetext{
7 Thanks to two anonymous referees for this journal for pressing me on this.
} 
to suppose that the concept of an epistemic reason is best understood as the concept of a mind-independent entity. We can then reason as follows:

(3) It is a fact that wet streets are a reason to believe that it is raining.

(4) So, there is at least one epistemic fact.

As before, it is not clearly more plausible that the world contains no epistemic facts than that wet streets are a reason to believe that it is raining. Since the truth of (3) requires the existence of mind-independent normative facts, we have reason to accept at least one mind-independent normative fact.

I do not claim to have established that realists have excellent reasons for postulating mind-independent normative truths (in fact, I doubt this on the whole). But I also doubt that Street would claim to have refuted all possible arguments for realism on the basis of her dilemma for realists about epistemic normativity. She was primarily interested in showing that realism is inconsistent with the constitutive-takings account of belief, and that rejection of the account would lead them to postulate scientifically dubious tracking mechanisms. I have argued that neither is the case.

\section{Conclusion}

Street raised a dilemma for realists about epistemic normativity. If they accept the constitutive-taking account of belief, they would not be able to be realists about epistemic normativity. But if they reject the constitutive-takings account, they would lack a scientifically credible explanation of the fact that our epistemic behaviours and beliefs about epistemic reasons align with independent normative truths. I've argued that it is unclear why acceptance of the constitutive-takings account would be incompatible with normative realism about Cliffordian normativity or normative realism about likelihood. I have also argued that if realists reject the constitutive-takings account of belief, they may still have scientifically credible explanations of the fact that our epistemic behaviours and beliefs about epistemic reasons align with independent normative truths about them.

Acknowledgments Thanks to the audience at the Stockholm/Uppsala Joint Seminar in Practical Philosophy. Special thanks to Krister Bykvist for helpful comments.

Open Access This article is distributed under the terms of the Creative Commons Attribution License which permits any use, distribution, and reproduction in any medium, provided the original author(s) and the source are credited.

\section{References}

Cuneo, T. (2007). The Normative web: An argument for moral realism. Oxford: Oxford University Press. Cuneo, T., \& Shafer-Landau, R. (2014). The moral fixed points: New directions for moral nonnaturalism. Philosophical Studies, 171(3), 399-443.

Kirchin, S. (2012). Metaethics. London: Palgrave MacMillan.

Mackie, J. (1978). Ethics: Inventing right and wrong. Harmondsworth: Penguin.

Olson, J. (2014). Moral error theory: History, critique, defence. Oxford: Oxford University Press.

Shafer-Landau, R. (2003). Moral realism. A defence. Oxford: Oxford University Press. 
Shafer-Landau, R. (2006). Ethics as philosophy. A defence of ethical nonnaturalism. In R. Shafer-Landau (Ed.), Oxford studies in metaethics (pp. 210-232). Oxford: Oxford University Press.

Shafer-Landau, R. (2012). Evolutionary debunking, moral realism and moral knowledge. Journal of Ethics \& Social Philosophy, 7(1), 1-37.

Street, S. (2006). A Darwinian dilemma for realist theories of value. Philosophical Studies, 127(1), 109-166.

Street, S. (2009). Evolution and the normativity of epistemic reasons. Canadian Journal of Philosophy, 35(suppl.), 213-248.

Wedgwood, R. (2007). The nature of normativity. Oxford: Oxford University Press. 